\title{
COMPARISON STUDY BETWEEN USING AIR DATA AND SOIL DATA IN PREDICTING SOIL TEMPERATURE
}

\author{
S. HAMDANE ${ }^{1}$, P. D. SILVA ${ }^{2,5}$, L. C. C. PIRES ${ }^{3,5}$ AND A. MOUMMI ${ }^{4}$ \\ ${ }^{1}$ Mohamed Khider University, Laboratory of Mechanical Engineering (LGM), \\ BP145 Biskra 07000, Algeria, \\ samia.hamdane@univ-biskra.dz \\ ${ }^{2}$ University of Beira Interior, \\ Rua Marquêsd'Ávila e Bolama, 6201-001, Covilhã, Portugal, \\ dinho@ubi.pt \\ ${ }^{3}$ University of Beira Interior, \\ Rua Marquêsd'Ávila e Bolama, 6201-001, Covilhã, Portugal, \\ pires@ubi.pt \\ ${ }^{4}$ Mohamed Khider University, Laboratory of Mechanical Engineering (LGM), \\ BP145 Biskra 07000, Algeria, \\ a.moummi@univ-biskra.dz \\ ${ }^{5}$ C-MAST - Centre for Mechanical and Aerospace Science and Technologies Covilhã, 6200-001, \\ Portugal
}

Key words: Soil Temperature, Reference Year, Depth, Air Data, Soil Data.

\begin{abstract}
: soil in shallow depths could be used as heat sink / heat source for cooling / heating devices. To predict its thermal behaviour during year, some authors use data from soil temperature records some else use data from average yearly air temperature measurements of meteorologic stations to avoid measure soil temperature in shallow depths for long time. In this research paper, we present a comparison study about the use of soil data and the use of air data for soil temperature prediction, where transient heat conduction in semi-infinite solids is utilised in the study. We measured the soil temperature of three sites for three years in Covilha -Portugal to support the current study. Later, we create reference years of soil temperature in the three sites.
\end{abstract}

\section{INTRODUCTION}

Underground builds and systems such as earth air heat exchanger (EAHE) and ground heat pump (GHP) are very useful to conserve energies in the cooling / heating operations [1]. Predicting soil thermal behaviour during the year according to its properties and climatic conditions is important for installing and designing cooling / heating systems and builds in way that eliminate the need for extra materials and distances, so achieving maximum decrease of energy consumption. Several researchers have studied the ground heat distribution using experimental investigations and mathematical models.

Experimental setup carried out by Sydney and Baggs [2] to study the surface ground 
temperature and determining the available and suitable sites to install the previous mention systems, where they presented an isothermal contour map using the long-term ground temperature records, that exist in 20 sites around five states of Australia. Popiel, Wojtkowiak [3] did comparison of covered soil and bare soil (lawn and car park). They declare that underground temperature bellow $1 \mathrm{~m}$ in winter season is almost the same in both sites. While in summer season, the ground temperature under car park were higher about $4{ }^{\circ} \mathrm{C}$, as compared with the ground temperature under short grass (lawn). Another experimental investigation by Popiel and Wojtkowiak [4] studied experimentally the variations of disturbed soil depth. The measurements show that disturbed soil depth depends the sun irradiation according to seasons, where that depth changes between $0.1 \mathrm{~m}$ in winter and 0.35 $\mathrm{m}$ in summer. Experimental investigation conducted by Chow, Long [5] and Pokorska-Silva, Kadela [6] to understand the relation between average ambient air temperature and undisturbed soil temperature, under $3 \mathrm{~m}$ of depth for lawn condition. Authors declare that the ground heat distributions depend strongly the dry air temperature, while the effects of the relative humidity, rainfall, global solar radiation and wind speed are weak. Pouloupatis, Florides [7] highlighted the relation between ground composition and its temperature, where the measurements of ground temperature for 3 different sites up to $7 \mathrm{~m}$ of depth shows almost no differences regardless the differences in the composition of the ground. The disturbed ground depth depends on the temperature variations, while ground temperature in undisturbed depth is constant during the year $[8,9]$.
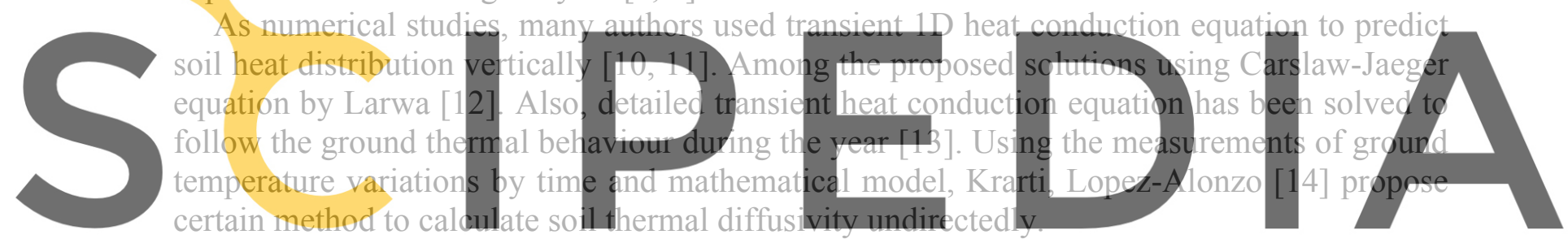

For analytical solutions, transient 1D heat conduction equation was strongly used [4, 15-

Register $\mathrm{f} \nexists \mathrm{P}]$ free at https//www.scipedia.com to download the version without the watermark

In modelling ground thermal distribution, several authors were interested in finding relation between ambient air and undisturbed soil temperatures [21]. Some other were interested about predicting soil temperature with less input $[10,17]$. Some else, highlighted the geology of multilayer in ground and the different effect of thermal properties [11]. Also, several studies have taken the climatic conditions into account (inland, south-Mediterranean, central and northern Europe, variable, humid continental, moderate, arid, domestic, moderate and arid climates) $[5,7,10,12,14,15,17,18,20]$.

Among the researches cited above, many authors used the average yearly air temperature measurements from meteorologic stations in certain site to calculate the mean yearly air temperature and its yearly amplitude, where they mentioned that it simulate the undisturbed soil temperature and soil surface thermal wave amplitude, respectively $[12,19,20]$. In the present work, we realize a comparison study about using air data and using soil data to predict the soil temperature in shallow depths. To develop this research, we measured the ground temperature for 3 years (16/05/2016 until 13/05/2019) in 3 different places (Covilha Portugal), from 1 to $5 \mathrm{~m}$ of depths. Air data and soil data are utilised as input parameters for the transient heat conduction in semi-infinite solids model to predict the soil thermal distribution. Then, we select the special data of each site to create the reference years that 
describe soil thermal behaviour in three sites of Covilha -Portugal in shallow depths.

\section{ANALYTICAL MODEL}

We suppose that each site is homogeneous. Then, we have changed the thermal diffusivity values in literature ranges [22], according to soil texture in Table 1, to reach better agreement in model results with experimental data. This proceeding is applied only in $1^{\text {st }}(\mathrm{m})$ depth, where the thermal diffusivities that obtained are used in the other depths. Warmest week in year is defined as $t_{0}$. Its values according to soil temperature records are 15,17 and 16 (weeks) after 16 May in the 3 years of experiences, for A, B and C sites, respectively.

The mathematical model is developed using transient $1 \mathrm{D}$ heat conduction equation for homogenous solid [15].

$$
\frac{1}{\alpha} \frac{\partial T}{\partial t}=\frac{\partial^{2} T}{\partial z}
$$

\section{Boundary condition}
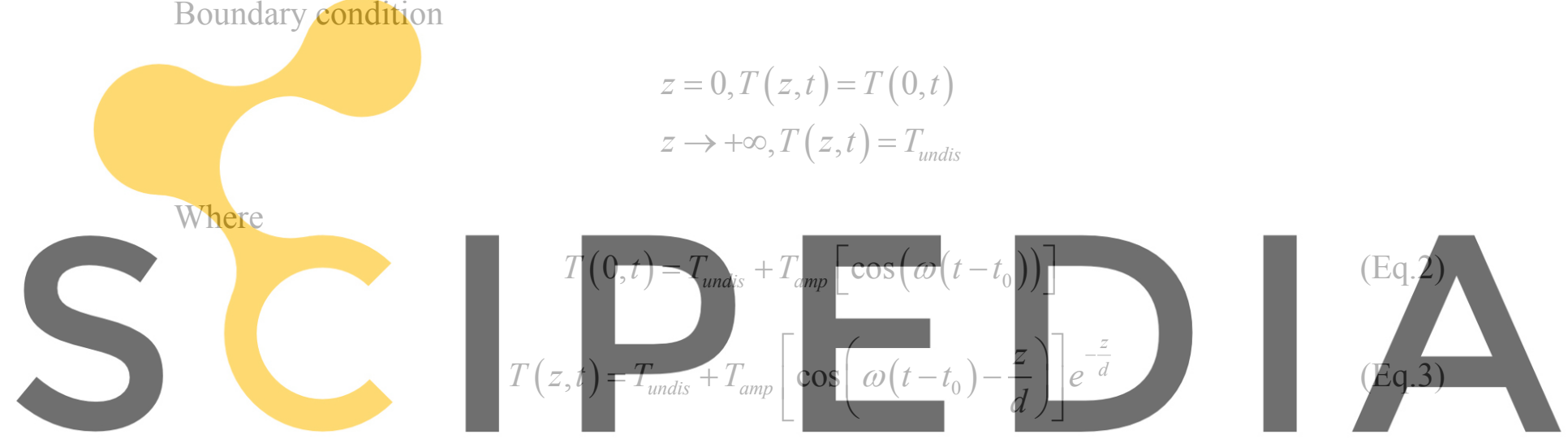

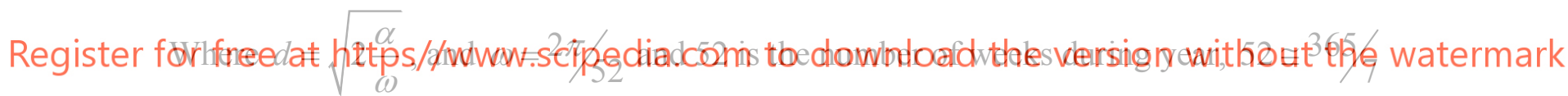

$T_{\text {amp }}$ is the soil temperature wave amplitude in $z=0(\mathrm{~m})$

Where $t$ is the time (weeks), $\omega$ is the annual angular frequency ( $r a d$. week $^{-1}$ ) and $\alpha$ is the soil thermal diffusivity $\left(\mathrm{m}^{2}\right.$. week $\left.{ }^{-1}\right)$.

\section{EXPERIMENTAL STUDY}

\section{III.1. Purpose and description}

The purposes of realize these experiences are to use the soil temperatures records in:

- Calculate parameters that needed in the previous mathematical model to predict soil temperature (soil thermal wave amplitude and average soil temperature).

- Show the preciseness of model results in predicting soil temperature for different sites, using air data from meteorological station as compared with experimental records.

- Create reference year for soil temperature in each site. 
Experimental sites were realized in 2016, Covilha (Portugal). It has been perforating the ground vertically to $5(\mathrm{~m})$ in 3 sites. After that, specific probes have been created by injecting 5 thermocouples in plastic pipes with $1(\mathrm{~cm})$ of diameter. Each thermocouple in the probe is designed to measure soil temperature in different depths from $1(\mathrm{~m})$ to $5(\mathrm{~m})$ Ground surface in site $\mathrm{A}$ is covered by trees. It is located between buildings and stream and the distance between stream and site is about $4(\mathrm{~m})$, while the stream depth is about $5(\mathrm{~m})$. Ground surfaces in sites $\mathrm{B}$ and $\mathrm{C}$ are bare. Those last exist in hill, where site $\mathrm{B}$ exhibit in front solar in part of day (morning period) and site $\mathrm{C}$ exhibit in front solar in all daytime.

\section{III.2. Soil analysis}

Samples from the sites A, B and C have been taken (Figure 1). Protocol that used in analysing those samples is soil sifting after drying it (Figure 2), where it has been found 3 type of soil composition, (Table 1)

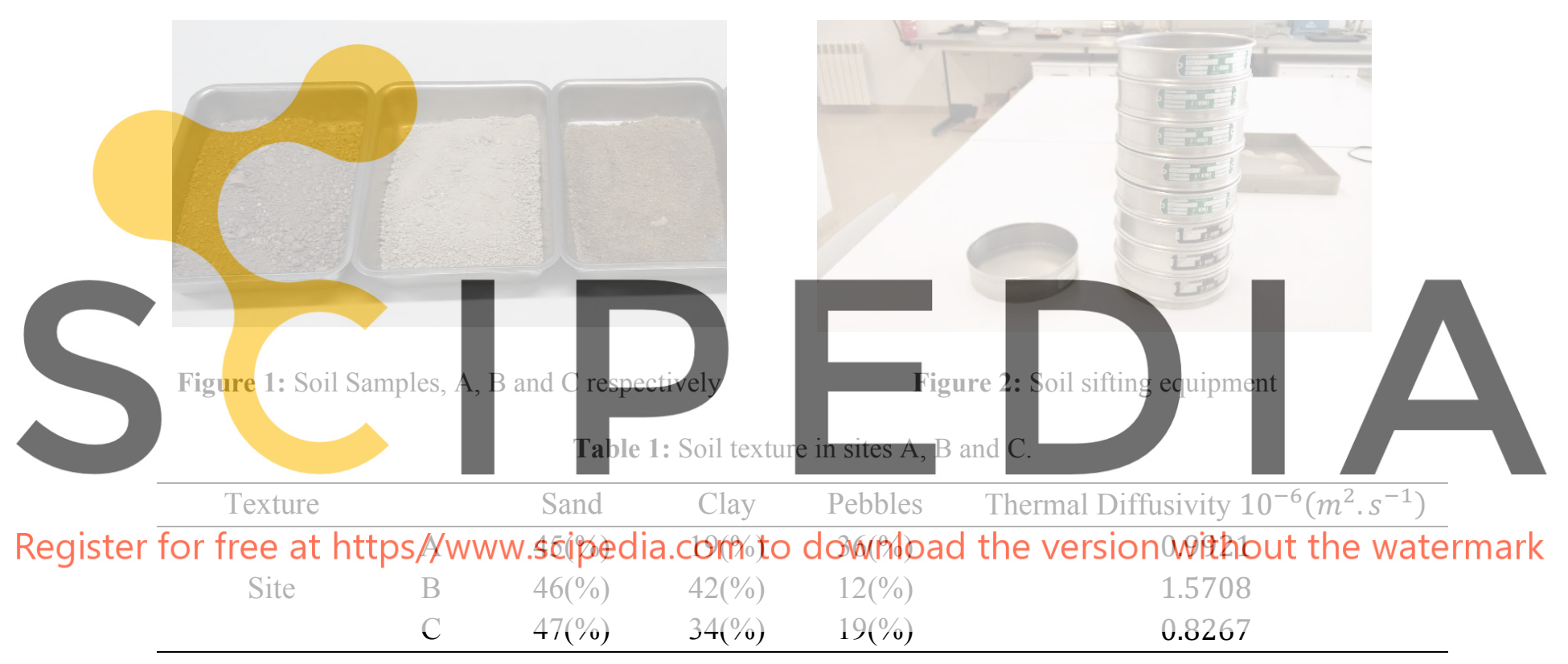

\section{III.3. Equipment details}

Thermocouples that used in the experiences are type $\mathrm{T}$, where this type has larger range of temperature measurements (Figure 4). Datalogger that used has 12 canals. Canals accept all thermocouple types. Its accuracy together with thermocouple is $\Delta T= \pm 0.5\left({ }^{\circ} \mathrm{C}\right)$ 


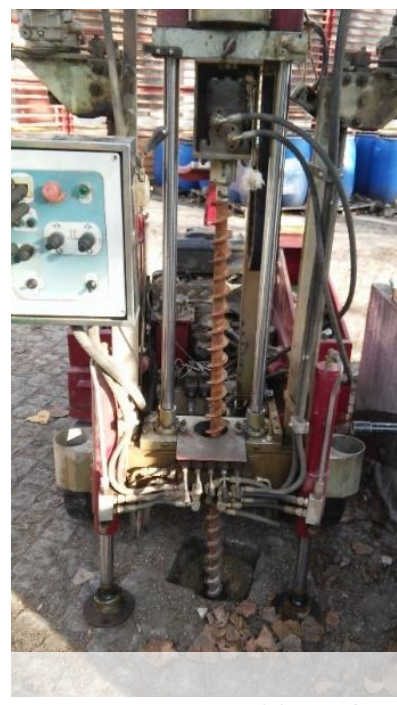

Figure 3: Machine of perforate

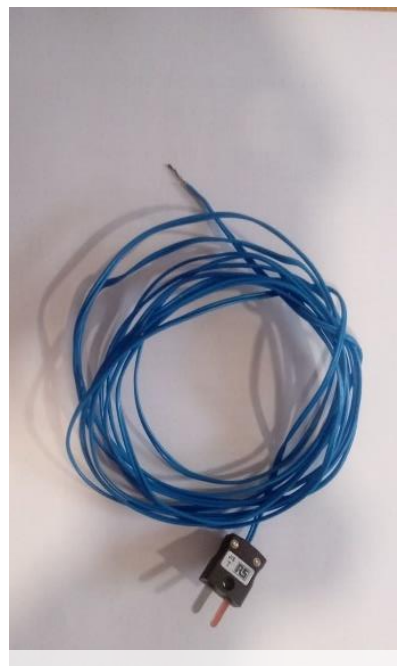

Figure 4: Thermocouple type T

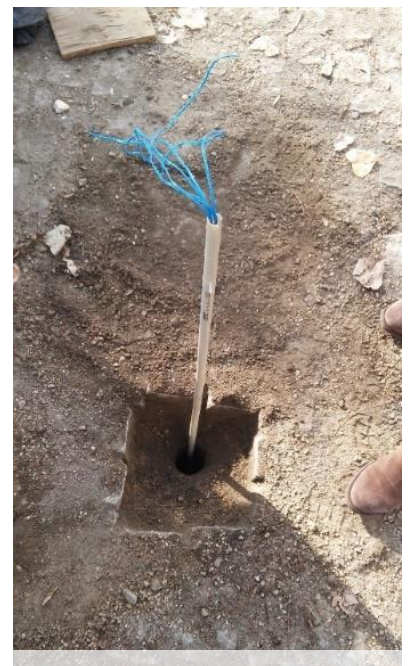

Figure 5: Probe injected in perforated hole

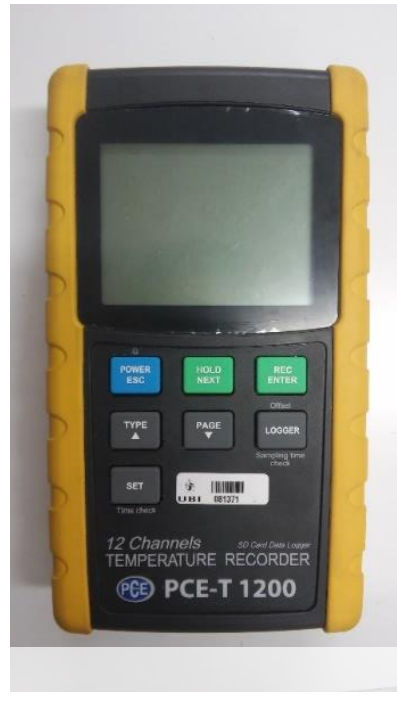

Figure 6: Datalogger

\section{RESULT AND DISCUSSION \\ IV.1. Soil data}

the soil temperature records are gathered in Table 2. We add datalogger indication degrees

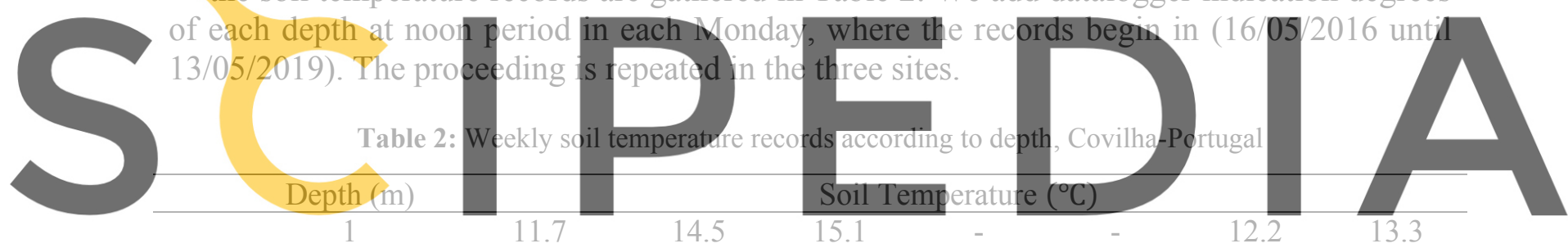

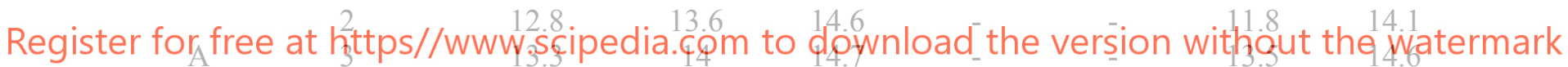

\begin{tabular}{ccccccccc} 
& 4 & 13.9 & 14.6 & 15.2 & - & - & 14.3 & 15.2 \\
& 5 & 14.8 & 15.4 & 15.9 & - & - & 15.5 & 15.4 \\
\hline & 1 & 11.9 & 13.2 & 14.2 & - & - & 10.3 & 13 \\
& 2 & 11 & 10.6 & 12.1 & - & - & 12.2 & 12.1 \\
& 3 & 11.2 & 11.1 & 11.7 & - & - & 12.9 & 9.9 \\
& 4 & 10.6 & 10 & 10.9 & - & - & 13.5 & 10.6 \\
& 5 & 10.2 & 10.3 & 11.2 & - & - & 14.8 & 14.5 \\
\hline & 1 & 12.3 & 14.8 & 15.9 & - & - & 11.1 & 12.2 \\
& 2 & 11.5 & 11.4 & 13.9 & - & - & 12.3 & 11.3 \\
& 3 & 11.9 & 11.8 & 12.9 & - & - & 13.1 & 10.2 \\
& 4 & 10.7 & 10.1 & 11.7 & - & - & 13.5 & 10 \\
& 5 & 11.3 & 11.4 & 12 & - & - & 13.2 & 9.7 \\
\hline
\end{tabular}

Ground control volume is the soil from 1 to $5(\mathrm{~m})$ of depths. It has been used the records of $1(\mathrm{~m})$ of depth to calculate the ground thermal wave amplitude (Table 3). Also, it has been calculated the mean ground temperature records in 5 (m) depth to use as undisturbed temperature for each site (Table 4). 
Table 3: Ground thermal wave amplitude.

\begin{tabular}{cccccc}
\hline Time (year) & & $2016 / 2017$ & $2017 / 2018$ & $2018 / 2019$ & Average \\
\hline \multirow{3}{*}{ Temperature $\left({ }^{\circ} \mathrm{C}\right)$} & $\mathrm{A}$ & 7.4 & 7.8 & 9.0 & 8.1 \\
& $\mathrm{~B}$ & 7.7 & 6.2 & 5.7 & 6.5 \\
& $\mathrm{C}$ & 9.8 & 9.1 & 7.7 & 9.0 \\
\hline
\end{tabular}

Ground thermal wave amplitude is important information. Using Equation 3 minus $T_{\text {undis }}$ allows user to calculate the depth of undisturbed temperature in soil, which call also damping depth. The present model shows damping depth in 10(m) for A and C sites and in $11(\mathrm{~m})$ for B site (Figure 7).

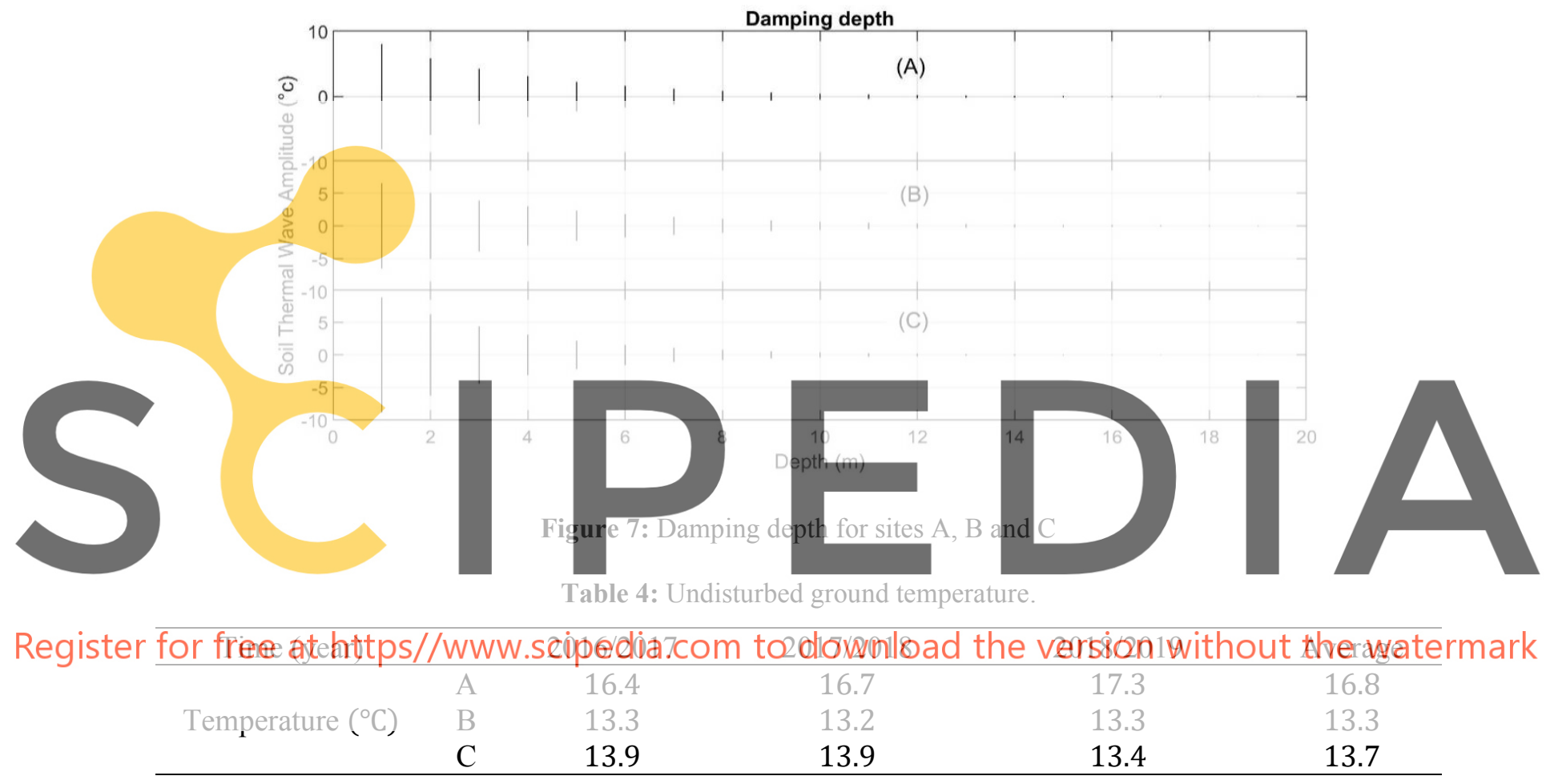

\section{IV.2. Air data}

Typical reference year for air temperature in Covilha from meteorological data bases of SolTerm software is used to calculate the air thermal wave amplitude and the average air temperature, where those values were $7.7\left({ }^{\circ} \mathrm{C}\right)$ and $12.1\left({ }^{\circ} \mathrm{C}\right)$ respectively $[23]$.

\section{IV.3. Validation and verification}

To predict the soil temperature for 2018/2019, we use soil data from Tables 3 and 4 in 2018/2019 as input for Equation 3. Also, we use air data as input for Equation 3. The experimental records of soil temperatures in 2018/2019 of A, B and C sites are used to validate the model results. Also, the use of soil data and air data are verified together in Figure 8 until Figure 12. 


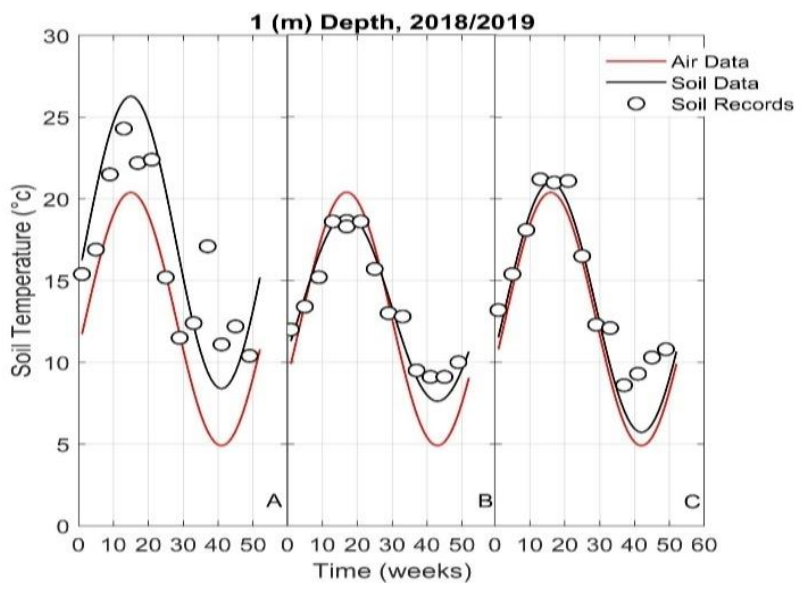

Figure 8: Validation and verification of model results with ground temperature records for 2018/2019 in A, $\mathrm{B}$ and $\mathrm{C}$ sites, under $1 \mathrm{~m}$ ) depth
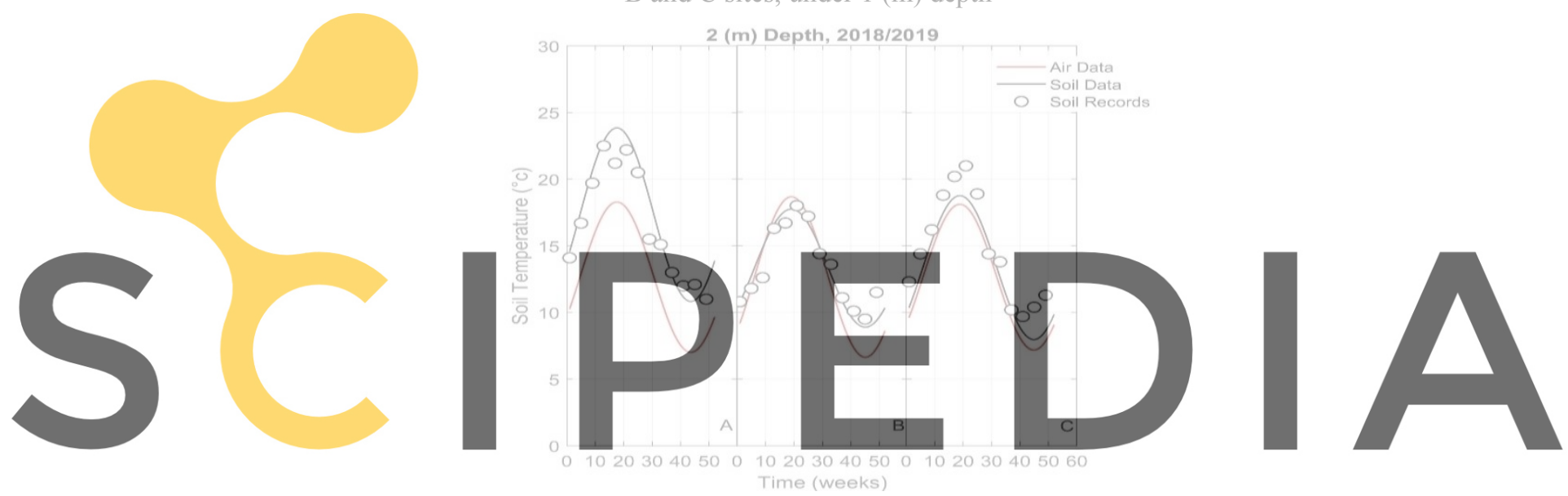

Register for free aththtps//www.scipedia.com to download the version without the watermark $\mathrm{B}$ and $\mathrm{C}$ sites, under $2(\mathrm{~m})$ depth

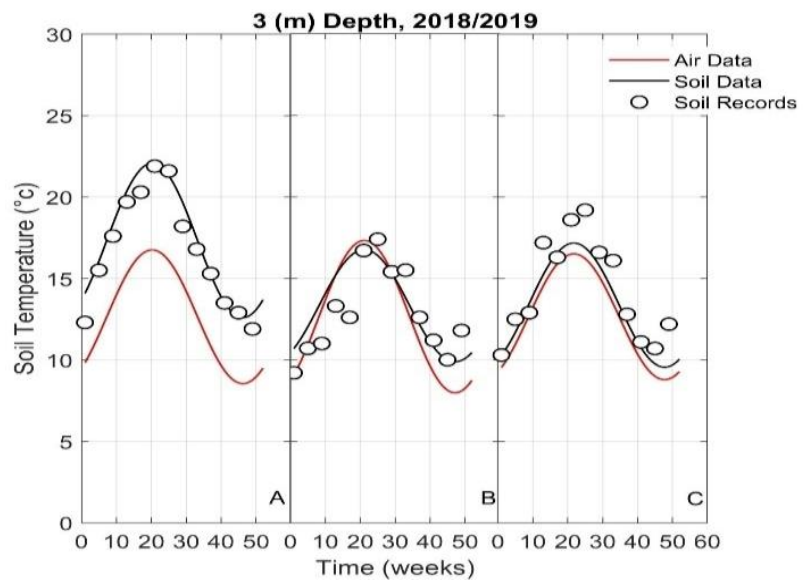

Figure 10: Validation and verification of model results with ground temperature records for 2018/2019 in A, $\mathrm{B}$ and $\mathrm{C}$ sites, under $3(\mathrm{~m})$ depth 


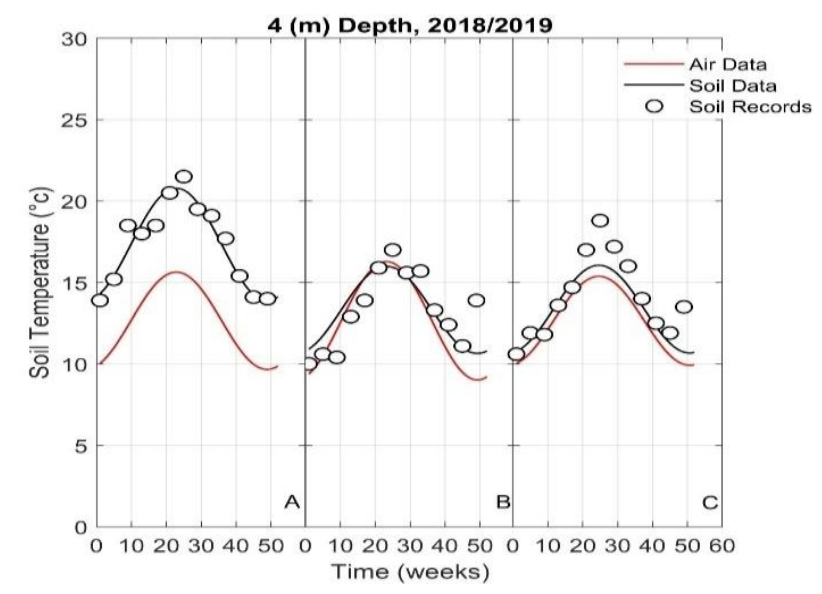

Figure 11: Validation and verification of model results with ground temperature records for 2018/2019 in A, $\mathrm{B}$ and $\mathrm{C}$ sites, under 4 ( $\mathrm{m}$ ) depth
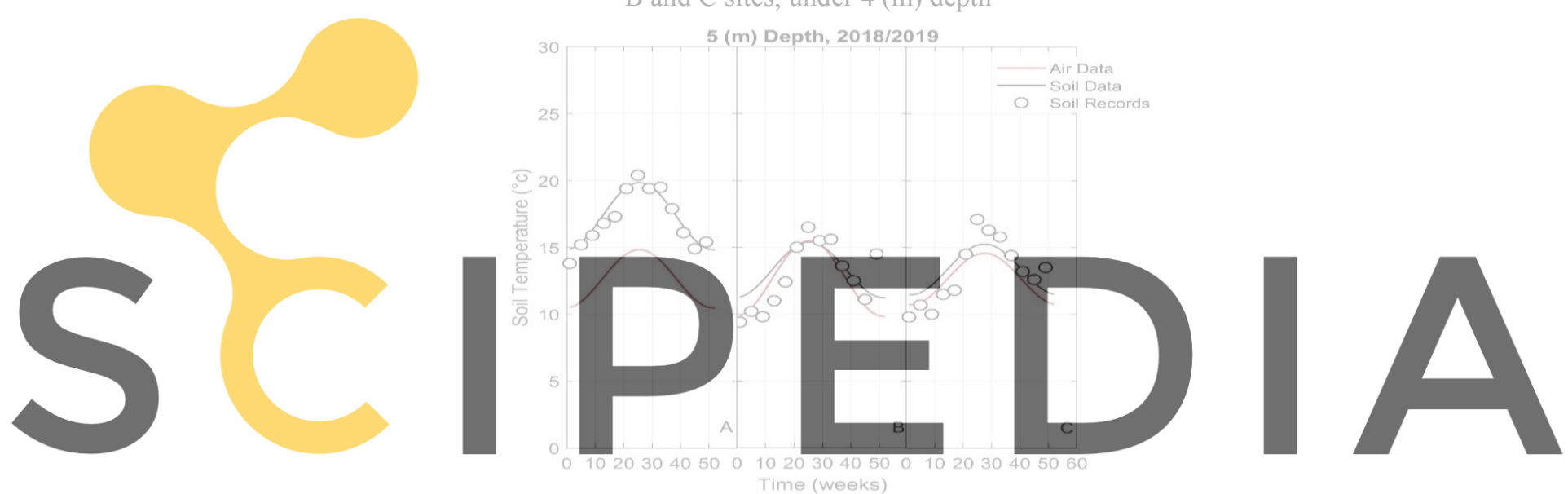

Register for free at https/fwww. scipedia.com to download the version without the watermark $\mathrm{B}$ and $\mathrm{C}$ sites, under $5(\mathrm{~m})$ depth

Using the soil data gives better agreements in predicting soil temperature with experimental records in all depths and in all sites. The use of average ambient air temperature in predicting soil temperature in site $\mathrm{B}$ and $\mathrm{C}$ gives better agreements as compared with site $\mathrm{A}$ (Figures 8 until 12).

\section{IV.4. Create soil temperature reference year}

The average soil data that are mentioned in Tables 3 and 4 are distinguishing parameters to create the reference years for each site. To show the validity of the created reference years, we compare it with the calculated soil temperature differences from the 3 years records $(16 / 05 / 2016$ until 13/05/2019), where the differences values are used as weekly bars. The average difference was $2\left({ }^{\circ} \mathrm{C}\right)$ in $\mathrm{A}, \mathrm{B}$ and $\mathrm{C}$ sites for all depths (Figures 13 until 17). 


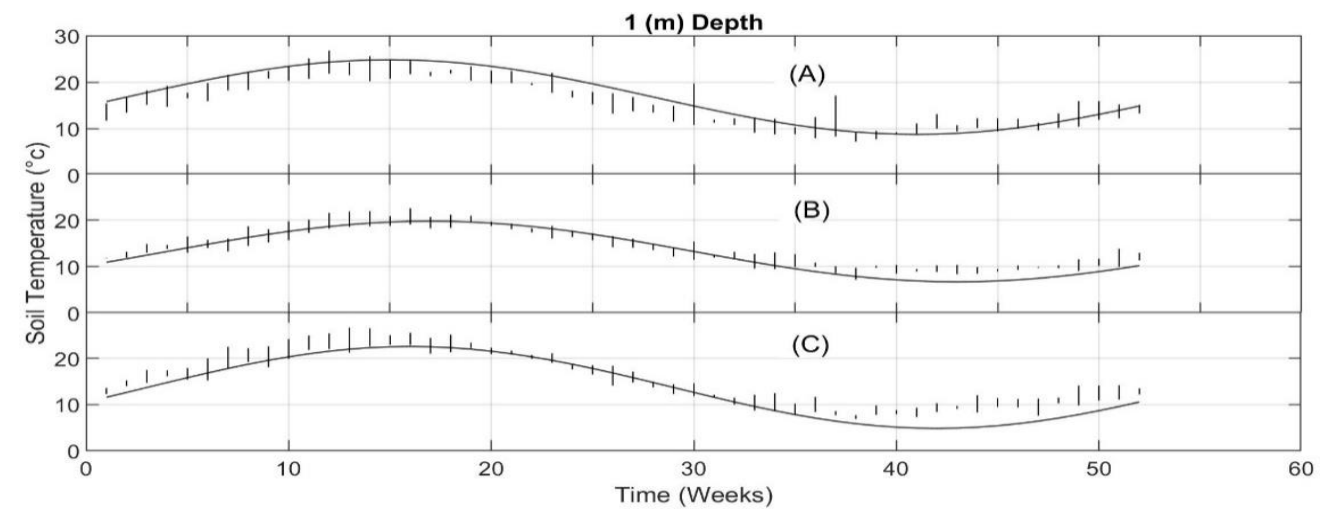

Figure 13: Validation of soil temperature reference years in A, B and C sites, under 1 (m) depth
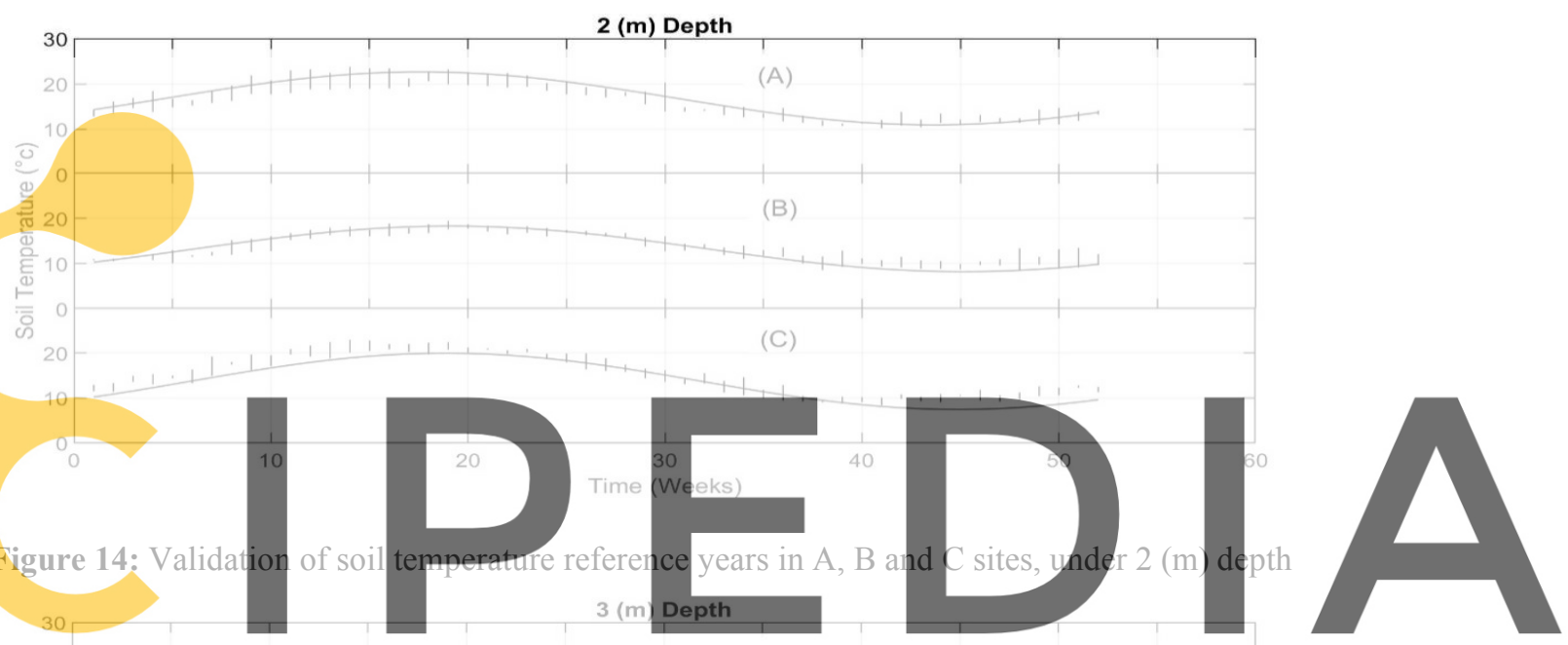

Register for free at https//www.scipedia.com to download the version without the watermark

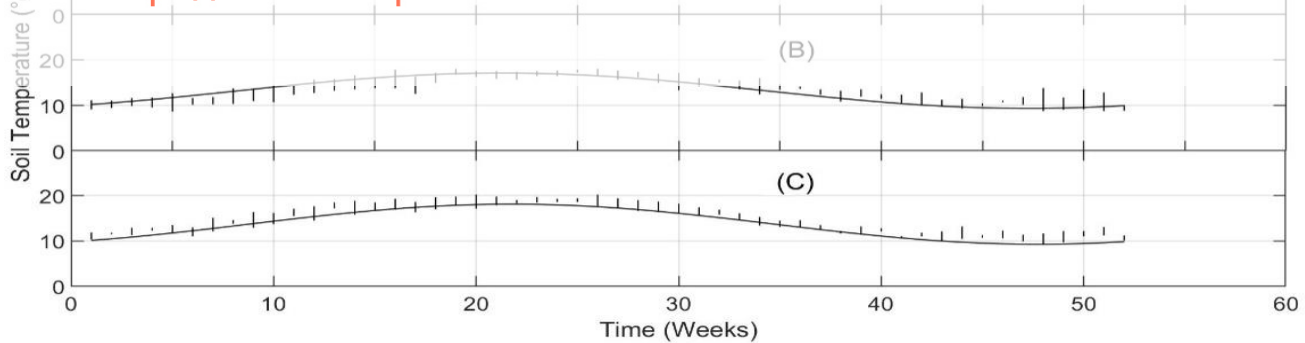

Figure 15: Validation of soil temperature reference years in A, B and C sites, under 3 (m) depth 


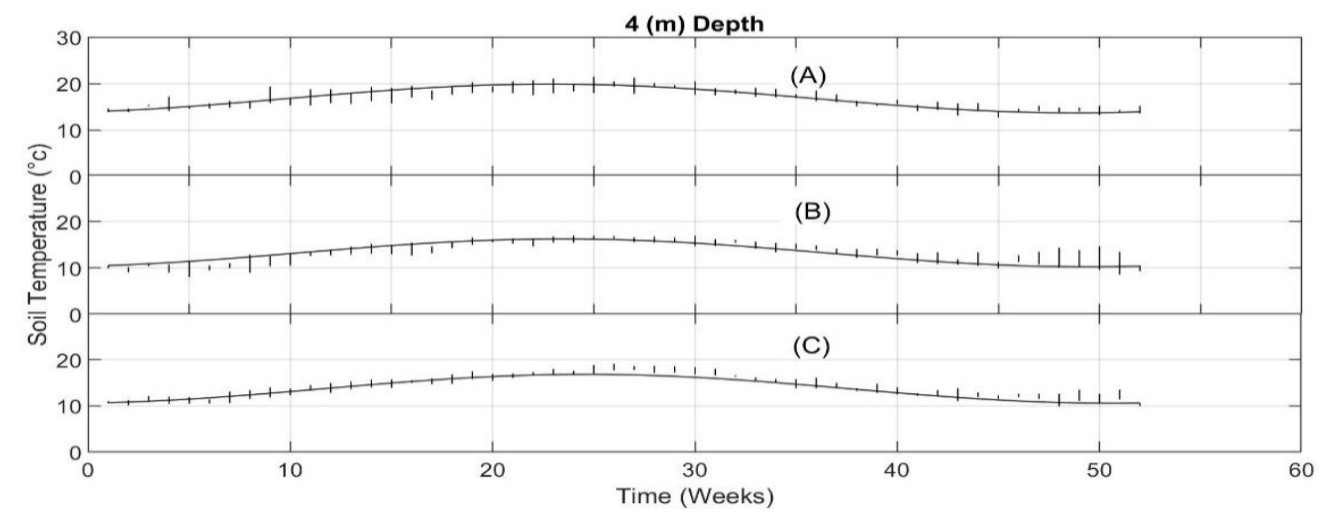

Figure 16: Validation of soil temperature reference years in A, B and C sites, under 4 (m) depth
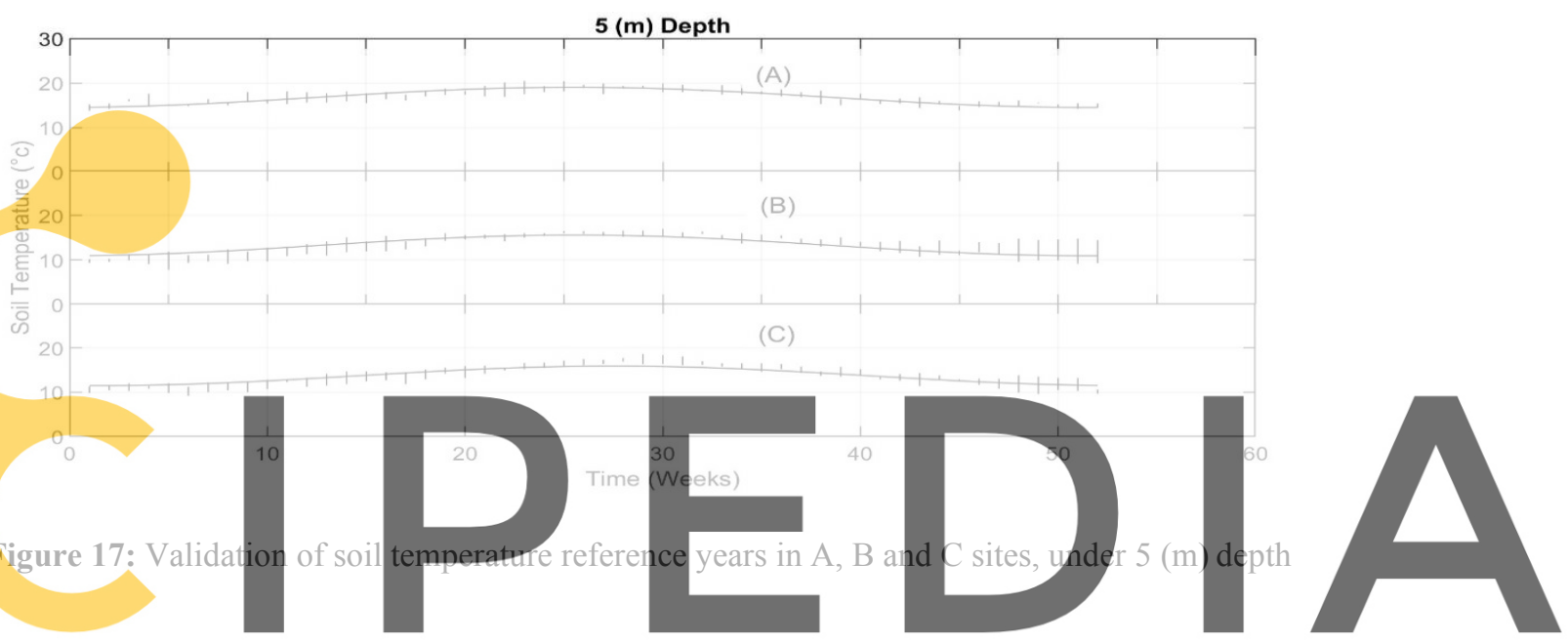

Register for free at https//www.scipedia.com to download the version without the watermark

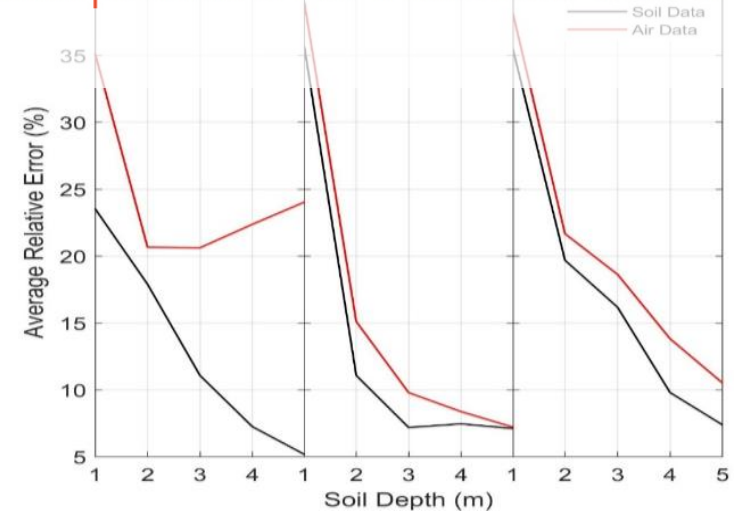

Figure 18: Average relative errors of using air data / soil data in predicting soil temperature of 3 years as function by depth. 
We have used the soil temperature records of each year to validate and to compare the model results when using the soil data of reference year and using air data to predict the soil temperature in shallow depths, where average relative errors is showed in the Figure 18. The use of air data in predicting soil temperature in cases $\mathrm{B}$ and $\mathrm{C}$ gives better agreements as compared with case A. Also, the use of soil data in predicting the soil temperature gives better agreements as compared with the results of using air data.

\section{CONCLUSION}

- In practical terms the average yearly air temperature can be used to define the air data that used in predicting the soil temperature in shallow depths. This procedure avoids having to measure the soil temperature at greater depths however the error is higher.

- Using air data in some cases (A for example) gives high relative error, where the difference between mean air temperature and undisturbed soil temperature is $4\left({ }^{\circ} \mathrm{C}\right)$.

- Reference years of soil temperatures are useful to select the available sites for the wanted function (pre-heating or pre-cooling).

- The sites B and C have low undisturbed ground temperature. They are good sites to install EAHE as pre-cooler system.

- Site A has higher undisturbed temperature. It gives better results as pre-heater with EAHE system.

\section{REFERENCE}

1. Hamdane, S., C. Mahboub, and A. Moumi, Numerical Approach to Predict the Outlet Temperature of Earth-to-Air-Heat-Exchanger. Thermal Science and Engineering Progress, 2020: p. 100806.

2. Sydney, A. and Baggs, Remote prediction of ground temperature in Australian soil and mapping its distribution. Solar Energy, 1983. 30(4): p. 351-366.

3. Popiel, C.O., J. Wojtkowiak, and B. Biernacka, Measurements of temperature distribution in ground. Experimental Thermal and Fluid Science, 2001. 25: p. 301309.

4. Popiel, C.O. and J. Wojtkowiak, Temperature distributions of ground in the urban region of Poznan City. Experimental Thermal and Fluid Science, 2013. 51: p. 135148.

5. Chow, T.T., et al., Estimation of soil temperature profile in Hong Kong from climatic variables. Energy and Buildings, 2011. 43(12): p. 3568-3575.

6. Pokorska-Silva, I., M. Kadela, and L. Fedorowicz, Variations of Ground Temperature in Shallow Depths in the Silesian Region. IOP Conference Series: Materials Science and Engineering, 2019. 603: p. 052024.

7. Pouloupatis, P.D., G. Florides, and S. Tassou, Measurements of ground temperatures in Cyprus for ground thermal applications. Renewable Energy, 2011. 36(2): p. 804814.

8. Florides, G.A., et al., The geothermal characteristics of the ground and the potential of using ground coupled heat pumps in Cyprus. Energy, 2011. 36(8): p. 5027-5036. 
9. Georgios, F. and K. Soteris, Annual ground temperature measurements at various depths. 2014.

10. Chalhoub, M., et al., A simple heat and moisture transfer model to predict ground temperature for shallow ground heat exchangers. Renewable Energy, 2017. 103: p. 295-307.

11. Zhou, S., et al., Study on ground temperature response of multilayer stratums under operation of ground-source heat pump. Applied Thermal Engineering, 2016. 101: p. 173-182.

12. Larwa, B., Heat Transfer Model to Predict Temperature Distribution in the Ground. Energies, 2018. 12(1): p. 25.

13. Ji, Y., H. Qian, and X. Zheng, Development and validation of a three-dimensional numerical model for predicting the ground temperature distribution. Energy and Buildings, 2017. 140: p. 261-267.

14. Krarti, M., et al., Analytical model to predict annual soil surface temperature variation. Journal of Solar Energy Engineering, 1995. 117(91).

15. Ben Jmaa Derbel, H. and O. Kanoun, Investigation of the ground thermal potential in tunisia focused towards heating and cooling applications. Applied Thermal Engineering, 2010. 30(10): p. 1091-1100.

16. Van Manen, S.M. and E. Wallin, Ground temperature profiles and thermal rock properties at Wairakei, New Zealand. Renewable Energy, 2012. 43: p. 313-321.

17. Badache, M., et al., A new modeling approach for improved ground temperature profile determination. Renewable Energy, 2016. 85: p. 436-444.

18. Al-Hinti, I., A. Al-Muhtady, and W. Al-Kouz, Measurement and modelling of the ground temperature profile in Zarqa, Jordan for geothermal heat pump applications. Applied Thermal Engineering, 2017. 123: p. 131-137.

19. Cho, S.-W. and P. Ihm, Development of a Simplified Regression Equation for Predicting Underground Temperature Distributions in Korea. Energies, 2018. 11(11): p. 2894.

20. Larwa, B. and K. Krzysztof, Study of temperature distribution in the ground. Chemical and Process Engineering, 2019. 40(1): p. 123-137.

21. Tsilingiridis, G. and K. Papakostas, Investigating the relationship between air and ground temperature variations in shallow depths in northern Greece. Energy, 2014. 73: p. 1007-1016.

22. Márquez, J.M.A., M.Á.M. Bohórquez, and S.G. Melgar, Ground Thermal Diffusivity Calculation by Direct Soil Temperature Measurement. Application to very Low Enthalpy Geothermal Energy Systems. Sensors, 2016.

23. Aguiar, R. and M.J. Carvalho, Performance analysis of solar thermal and photovoltaic systems, , 2012, Solterm software, National Laboratory of Energy and Geology Lisbon, Portugal,. 